
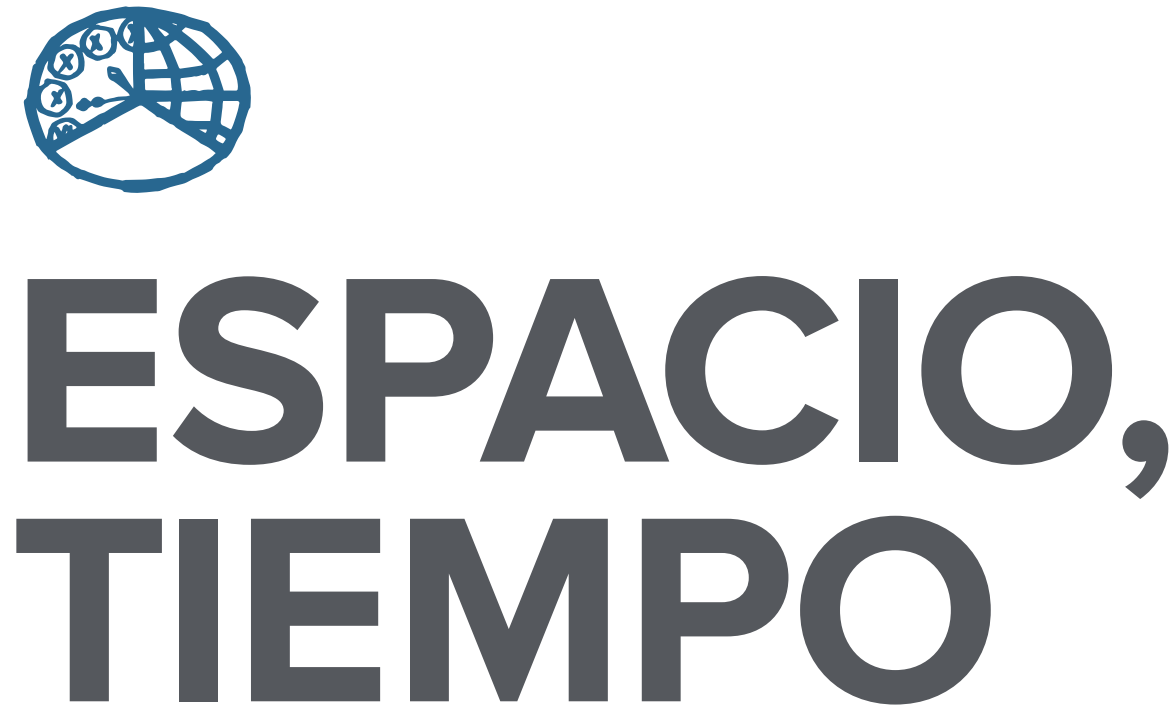

AÑO 2014

NUEVA ÉPOCA

ISSN 1130-4715

E-ISSN 2340-1478
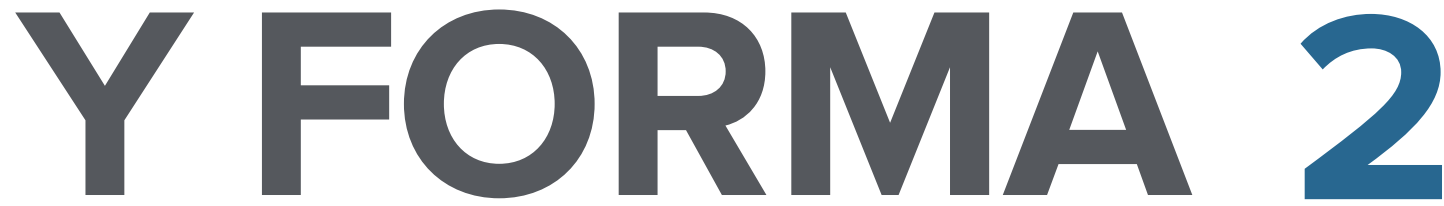

SERIE VII HISTORIA DEL ARTE

REVISTA DE LA FACULTAD DE GEOGRAFÍA E HISTORIA 

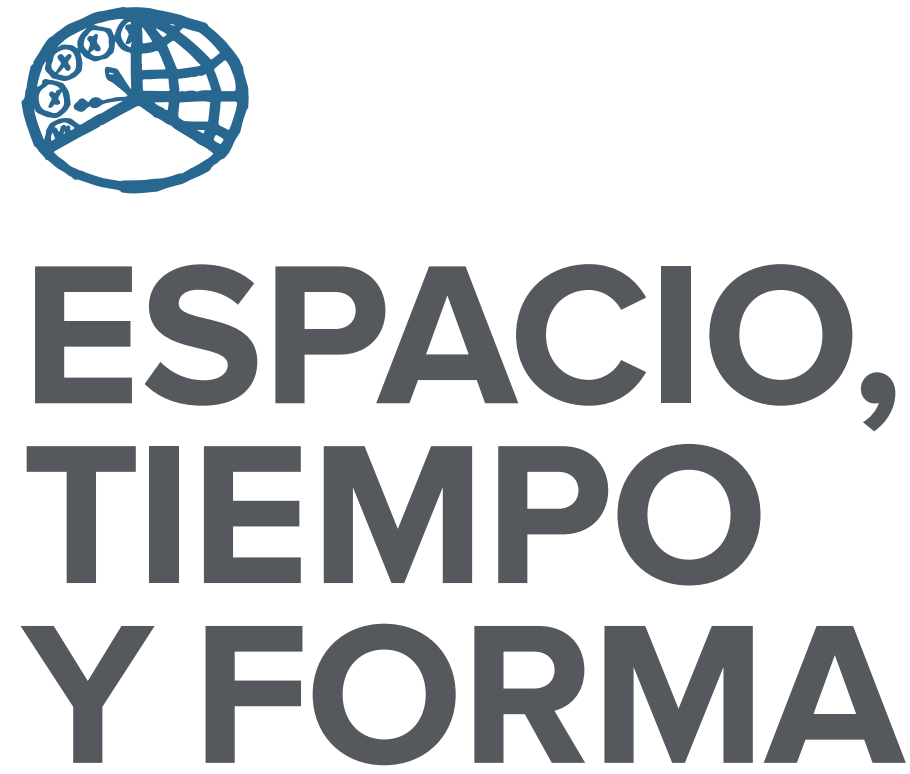

AÑO 2014

NUEVA ÉPOCA

ISSN $1130-4715$

E-ISSN 2340-1478

SERIE VII HISTORIA DEL ARTE

REVISTA DE LA FACULTAD DE GEOGRAFÍA E HISTORIA

http://dx.doi.org/10.5944/etfvii.2.2014

\section{UกED}

UNIVERSIDAD NACIONAL DE EDUCACIÓN A DISTANCIA 
La revista Espacio, Tiempo y Forma (siglas recomendadas: ETF), de la Facultad de Geografía e Historia de la UNED, que inició su publicación el año 1988, está organizada de la siguiente forma:

$$
\begin{aligned}
& \text { SERIE I - Prehistoria y Arqueología } \\
& \text { SERIE II - Historia Antigua } \\
& \text { SERIE III - Historia Medieval } \\
& \text { SERIE IV - Historia Moderna } \\
& \text { SERIE V - Historia Contemporánea } \\
& \text { SERIE VI - Geografía } \\
& \text { SERIE VII - Historia del Arte }
\end{aligned}
$$

Excepcionalmente, algunos volúmenes del año 1988 atienden a la siguiente numeración:

$$
\begin{aligned}
& \mathrm{N} .^{\circ} 1 \text { - Historia Contemporánea } \\
& \mathrm{N}^{\circ} 2 \text { - Historia del Arte } \\
& \text { N. }{ }^{\circ} 3 \text { - Geografía } \\
& \text { N. }{ }^{\circ} 4 \text { - Historia Moderna }
\end{aligned}
$$

ETF no se solidariza necesariamente con las opiniones expresadas por los autores.

Espacio, Tiempo y Forma, Serie vII está registrada e indexada, entre otros, por los siguientes Repertorios Bibliográficos y Bases de Datos: DICE, ISOC (CINDOC), RESH, IN-RECH, Dialnet, e-sPacio, UNED, CIRC, MIAR, FRANCIS, PIO, ULRICH'S, SUDOC, 2DB, ERIH (ESF).

\author{
UNIVERSIDAD NACIONAL DE EDUCACIÓN A DISTANCIA \\ Madrid, 2014 \\ SERIE VII · HISTORIA DEL ARTE (NUEVA ÉPOCA) N. ${ }^{\circ} 2,2014$ \\ ISSN $1130-4715 \cdot$ E-ISSN 2340-1478 \\ DEPÓSITO LEGAL \\ M-21.037-1988 \\ URL \\ ETF VII · HISTORIA DEL ARTE · http://revistas.uned.es/index.php/ETFVII \\ DISEÑO Y COMPOSICIÓN \\ Ángela Gómez Perea · http://angelagomezperea.com \\ Sandra Romano Martín · http://sandraromano.es \\ Impreso en España · Printed in Spain
}

(c) (1) (8) Esta obra está bajo una licencia Creative Commons

Reconocimiento-NoComercial 4.0 Internacional. 


\title{
DE NÁPOLES A MADRID: LA COLGADURA DE LOS ANIMALES DEL DUQUE DE MEDINA DE LAS TORRES
}

\section{FROM NAPLES TO MADRID: THE ANIMALS WALL HANGING OF THE DUKE OF MEDINA DE LAS TORRES}

\author{
Juan María Cruz Yábar ${ }^{1}$ \\ Recibido: 20/06/2014 · Aceptado: 29/10/2014 \\ http://dx.doi.org/10.5944/etfvii.2.2014.12245
}

\section{Resumen}

El príncipe de Stigliano donó al convento de Santa Teresa de Madrid una colgadura de gran valor, que ha sido objeto de estudio por diversos autores desde I9oo hasta la actualidad. Aportamos noticias sobre su datación y su origen extraídos de diferentes fuentes, profundizando en cuestiones como los componentes del conjunto, su estimación, la propiedad, vicisitudes sufridas a lo largo del tiempo, consideraciones estilísticas en relación con otras obras similares y sobre su iconografía humanista.

Palabras clave

Duque de Medina de las Torres; Príncipe de Stigliano; Nápoles; Madrid; colgadura

\section{Abstract}

The Prince of Stigliano donated to the convent of Santa Teresa in Madrid a very valuable wall hanging, which has been an object of study by several authors from I90o until nowadays. We are contributing news about its dating and origin, extracted from different sources, going into matters like the components of the collection, its respect, the property, vicissitudes that happened in the course of time, stylistic considerations in relation to other similar works and about its humanist iconography.

Keywords

Duke of Medina de las Torres; Prince of Stigliano; Naples; Madrid; wall hangings

1. Conservador. Departamento de Edad Moderna, Museo Arqueológico Nacional (juan.cruz@mecd.es). 


\section{DATOS HISTÓRICOS}

Las colgaduras son tejidos de seda - terciopelo normalmente, aunque también raso o tafetán-, con labores que pertenecen al género de los bordados, que se utilizaban para cubrir las paredes del mismo modo que los tapices, a los que superaban en efectos naturalistas gracias a los rellenos que daban relieve a algunas partes de su superficie y a los brillantes colores de los hilos de seda, oro y plata del bordado. Más delicadas que los tapices y de difícil conservación, las colgaduras se usaban preferentemente en verano e incluían, además de los paños para cubrir los paramentos, otras piezas complementarias como doseles, cenefas, asientos y almohadones a juego con los mismos motivos bordados.

La colgadura que nos ocupa, perteneciente al Museo Arqueológico $\mathrm{Nacional}^{2}$, está compuesta por nueve paños y procede del convento madrileño de carmelitas descalzas de Santa Teresa. Como especifica el expediente de adquisición de I8773 , fue donada al convento por don Nicolás María Felipe de Guzmán y Caraffa (I638-I689), príncipe de Stigliano - castellanizado Astillano-, duque de Sabbioneta, de Sanlúcar la Mayor y de Medina de las Torres, marqués de Toral y miembro del Consejo Real. En I900, Vignau ${ }^{4}$ consultó la escritura de fundación del cenobio, otorgada en I683 por el Príncipe y su mujer doña María Álvarez de Toledo, hija del duque de Alba. Señaló que la colgadura no perteneció al conde-duque de Olivares, como se venía afirmando, sino que los escudos que llevaba combinaban las armas de doña Anna Caraffa Gonzaga Colonna y Aldobrandini (I607-I644), princesa de Stigliano y duquesa de Sabbioneta 5 , madre de don Nicolás, y las de su esposo - con el que había casado en I636-, don Ramiro Felipe Núñez de Guzmán (h. I6oo-I668), duque de Medina de las Torres, marqués de Toral y virrey de Nápoles desde I637 hasta $\mathrm{I}_{644^{6}}$, y de ahí la confusión con el que fue su primer suegro ${ }^{7}$, el Conde-duque, ambos integrantes de la familia de los Guzmanes. Describió además los asuntos de los paños y dio a conocer una extensa documentación sobre la donación de la obra al convento por el príncipe de Stigliano y las dificultades que tuvieron las monjas para que pasara a su poder la colgadura.

Considerada milanesa, Castellanos Díaz ${ }^{8}$ la clasificó en I9I5 como flamenca por el influjo rubeniano - le recordaba a los tapices del Triunfo de la Eucaristía de las

\footnotetext{
2. Tienen los números de inventario 52632, 52642, 52649, 52653, 52674, 52675, 52690, 52699 y 52707.

3. Archivo Histórico del Museo Arqueológico Nacional, expediente 1877/17.

4. Vignau y Ballester, Vicente: «La colgadura del Convento de las Carmelitas Descalzas de Sta. Teresa», Revista de Archivos, Bibliotecas y Museos, Iv (1900), pp. 33-34.

5. Sobre la vertiente coleccionista de la Princesa, vid. Denunzio, Antonio Ernesto, «Anna Carafa» en MAfriCI, Mirella (coord.): Alla corte napoletana. Donne e potere dall'età aragonese al viceregno austriaco (1442-1734), Nápoles, Fridericiana Editrice Universitaria, 2012, pp. 189-199; también sobre su familia, Ibidem, «Sulla provenienza de // trionfo della Morte di Pieter Bruegel il Vecchio: le collezioni di Vespasiano Gonzaga tra Sabbioneta, Napoli e Madrid», Boletín del Museo del Prado, 47 (2011), pp. 6-15.

6. Acerca del carácter coleccionista del Duque, vid. Ibidem, «Alcune note inedite per Ribera e il collezionismo del duca di Medina de las Torres, viceré di Napoli» en Martínez Millán, J. \& Rivero Rodríguez, M., Centros de poder italianos en la Monarquía Hispánica (siglos XV-XVIII). Arte, música, literatura y espiritualidad, Madrid, Polifemo, 2010, vol. III, pp. 1981-2003.

7. Medina de las Torres casó en 1625 con doña Inés de Guzmán, hija única del Conde-duque.

8. Castellanos y díaz, María: Historia y técnica ornamental y decorativa de los bordados españoles. Madrid, Antonio G. Izquierdo, 1922, pp. 83-85.
} 


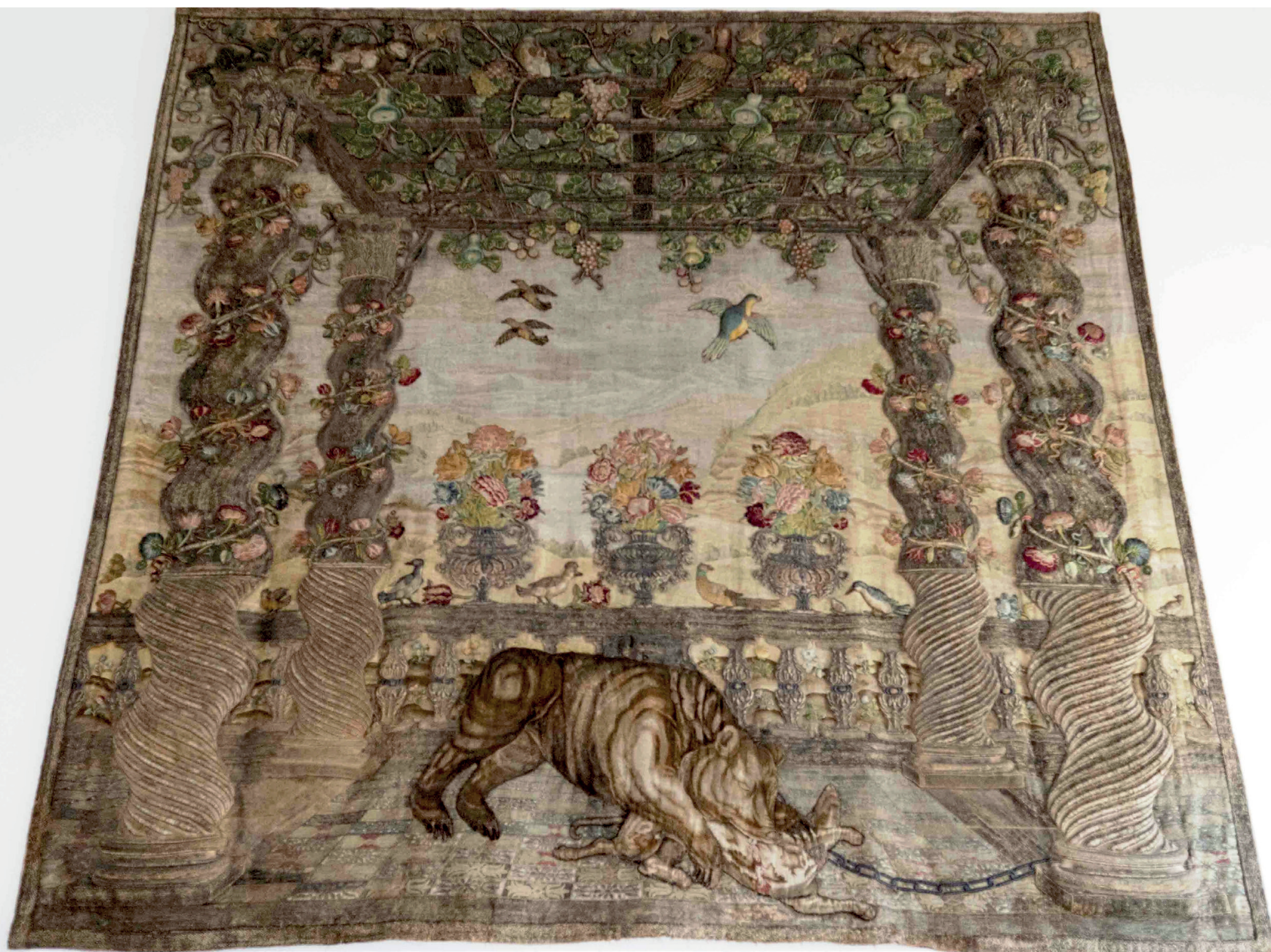

FIGURA 1. PAÑO DEL OSO Y EL PERRO

Madrid, Museo Arqueológico Nacional, n. ${ }^{\circ}$ inv. 52707. 
Descalzas Reales-y por la profusión de elementos florales y frutales, muy del gusto de los Países Bajos. Sánchez Amores publicó en 1985 un trabajo ${ }^{9}$ que incluía datos técnicos y descriptivos de la serie. No descartó totalmente un origen flamenco, aunque prefería el italiano por el tipo de templete con columnas salomónicas que remitían al baldaquino de Bernini en el Vaticano, la forma de presentar las flores y frutas, y la presencia en los escudos de las armas de Anna Caraffa. Señaló lo inusual de los motivos principales, animales diversos, a los que atribuyó un simbolismo zoomorfo en el estudio pormenorizado que hizo de cada uno de los paños y buscó fuentes literarias que correspondieran a ese significado oculto, como eran las virtudes que debían adornar al buen gobernante.

González Mena ${ }^{\mathrm{IO}}$ destacó el gran valor histórico, técnico y decorativo de la obra y su significado simbólico, y retornó a la tesis primitiva de su origen en alguna de las manufacturas milanesas de bordados. Por su parte, Taín Guzmán ${ }^{\text {II }}$ ha estudiado otra serie similar que se encuentra en la catedral de Santiago de Compostela, cuyos asuntos son mitológicos, considerando ambas colgaduras italianas. Respecto a la gallega, donada por Felipe Iv en I655, insistió en su decisiva influencia en el proyecto para el revestimiento interior del presbiterio de la Catedral que se hizo desde I658.

Bouza dio a conocer la existencia de diversos inventarios de bienes del duque de Medina de las Torres y su esposa la princesa de Stigliano hechos en Italia, pero se ocupó solo de las pinturas de la colección ${ }^{12}$. Ramírez Ruiz ${ }^{13}$ ha analizado las tapicerías de algunas colecciones nobiliarias españolas, en las que se incluyen las de Medina de las Torres, pero no menciona esta colgadura, al no ser objeto de su estudio debido a su diversa técnica.

Los citados inventarios permiten fechar con mucha aproximación el momento en que se hicieron los paños de la colgadura y confirman, además, su origen

9. SÁnChez Amores, Juliana: «Las colgaduras bordadas del convento de Santa Teresa de Jesús, de Madrid, en el M.A.N.», Boletín del Museo Arqueológico Nacional, III (1985), pp. 177-193.

10. González Mena, M. a Ángeles: «Bordado y encaje eruditos» en Bartolomé Arraiza, Alberto (coord.): Artes decorativas II. Summa Artis, Vol. xLV-II. Madrid, Espasa-Calpe, 1999, p. 114.

11. Taín Guzmán, Miguel: «Fuentes romanas gráficas y literarias del baldaquino y la pérgola de la Catedral de Santiago», Archivo Español de Arte, 314 (2006), pp. 151-155. La relación de esta serie y la del M.A.N. fue señalada ya por TORMO Y MONZó, Elías: «Las tapicerías de la Corona y de otras colecciones españolas», Boletín de la Sociedad Española de Excursiones, 156 (1906), p. 32, quién hizo hincapié en que las colgaduras bordadas no debían denominarse tapices.

12. BouzA, Fernando: «De Rafael a Ribera y de Nápoles a Madrid. Nuevos inventarios de la colección Medina de las Torres-Stigliano (1638-1656)», Boletín del Museo del Prado, 45 (2009), pp. 44-70.

13. Ramírez RuIz, Victoria: Las tapicerías en las colecciones de la nobleza española del siglo XVII, Tesis doctoral Universidad Complutense, Madrid, 2013. Ibidem, «La colección de tapices del ॥ Duque de Medina de las Torres y la Ix Condesa de Oñate», Goya, 344 (2013), pp. 208-219. 


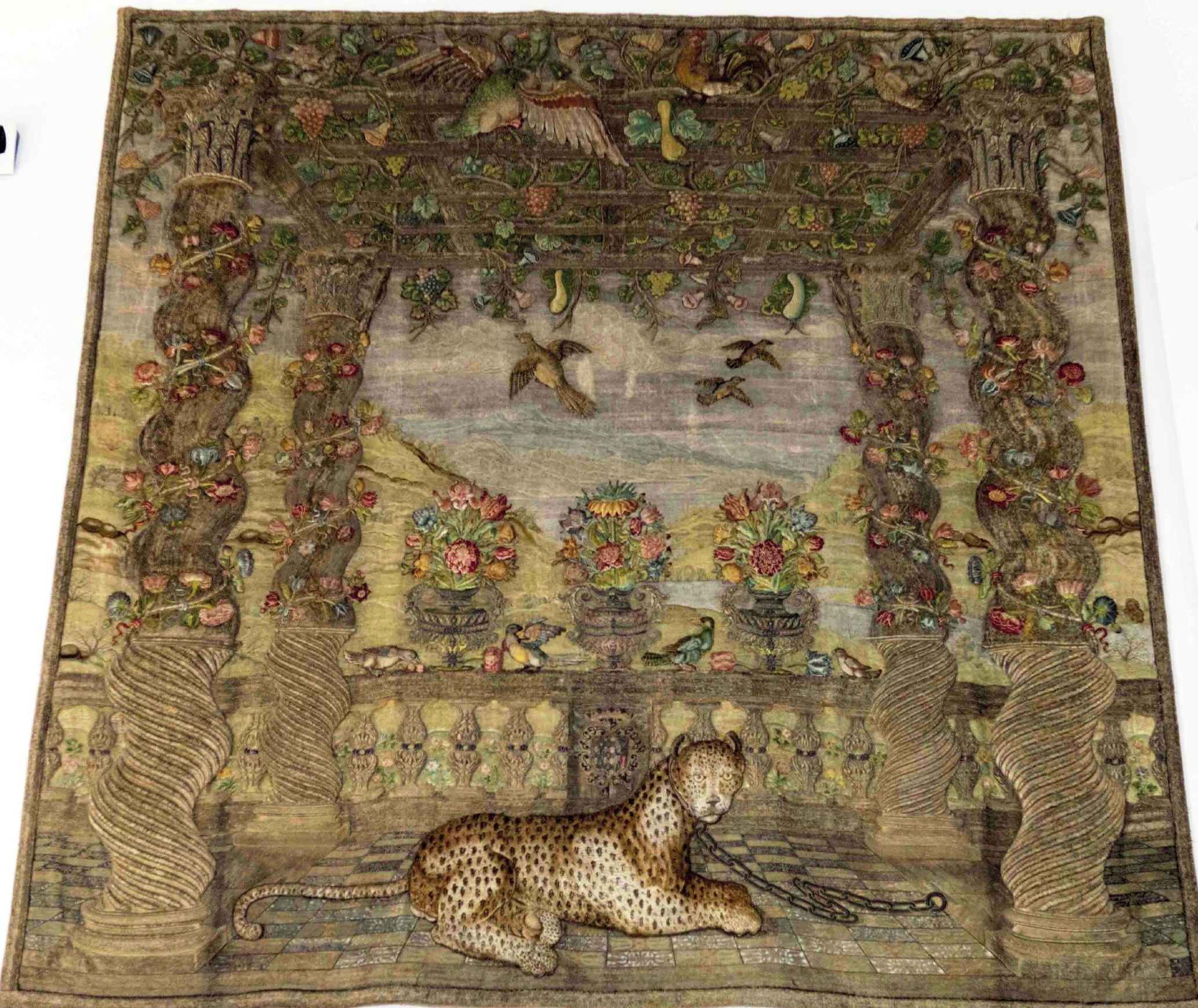

FIGURA 2. PAÑO DEL LEOPARDO

Madrid, Museo Arqueológico Nacional, n. ${ }^{\circ}$ inv. 52649. 
napolitano. Las relaciones más antiguas, de $\mathrm{I} 638^{14}, \mathrm{I} 639^{15}$ y $\mathrm{I} 64 \mathrm{I}^{\mathrm{I} 6}$, son registros de los bienes que existían en la casa del duque, pues se hicieron en los años en que era virrey y residía en Nápoles junto a su esposa, la princesa de Stigliano. Pues bien, en el último de los tres inventarios citados aparecen entre las partidas referentes a colgaduras bordadas:

Tre panni [tachado: per panni] per paramento di camera carrichi di racamo d'oro, eleta di più colori, et ogn'uno d'essi di palmi dieceotto in quadro con quattro colonne di racamo d'oro relevale per ciascheduno, che sostengono una pergola, sopara la quale diversi ucelli del naturale di basso relievo raccamati di seta di più colori, en el sfondato d'essa pergola lontananza de paesi, e vicinanza di colline con herbe, e fiori sopra, e ucelli, che volano, e per ciascuno d'essi tre napi di racamo d'oro co' fiori sopra del naturale, ad uno con un leone incatenato, all'altro un orso, che sbrana un cane, et all'altro una tigre incatenata con balagurhata d'oro per ciascheduno ${ }^{17}$.

La descripción es harto precisa y no cabe duda de que son tres de los nueve paños de colgadura que se han conservado hasta hoy en el museo madrileño. Las medidas, descritas como I8 palmos en cuadro, son aproximadamente las mismas ${ }^{\mathrm{I}}$. Se mencionan las pérgolas sostenidas por columnas y cerradas por una balaustrada, con un paisaje al fondo y colinas más cercanas con hierba, flores por encima y pájaros que vuelan, y, finalmente, una alfombra con flores sobre la que se sitúan sendos animales encadenados: un oso que despedaza un can (FIGURA I), una pantera - denominada tigre ${ }^{19}$ - (FIGURA 2), y un león (FIGURA 3) ${ }^{20}$.

Había a continuación otra partida con tres paños más que no formaban parte de la colgadura de los animales:

14. Archivo Histórico Nacional (AHN), Consejos suprimidos, leg. 51182/1/5. Guardarobba del 1638 e 1641 . // Inuentario della Guarda robba dell'Illmi et Eccmi Signori Duca de Medina de las torres et Eccma Sigra Prencipessa di Stigliano D. Anna Carrafa fatto a di 17 di Giugno 1638 di tutte le robbe notate al libro vecchio et altre no'notate in esso, consignate ad Alessandro Leticia Guardarobba di detti signori Eccmi. E di nuouo a di otto di luglio 1641 consignate ad Alessandro Becchi Roman nuouo Guardarobba per ordine di detti Signori Eccmi con Nota delli mancamenti ritrouati in ciascheda partita.

15. AHN, Consejos Suprimidos, leg. 51182/1/6. Inventario delle Gioie dell'Eccmi Sig.re Duca di Medina Las torres, et Eccma Sigra Principesca de Stigliano D. Anna Carrafa de Marra. Vicere et Viceregina nel Pnte Regno di Napoli fatto nell'anno 1639; Nota delle gioie portate da Spagna dall'lllmo et Eccmo Sigree Duca di Medina de las Torres all'Eccma Sigra Principesca DonAnna Carrafa; Gioie dell'Illma et Eccma Sigra Prencipessa di Stigliano DonAnna Carrafa di Marra.

16. AHN, Consejos suprimidos, leg. 51182/1/5. Guardarobba del 1638 e 1641 (vid. nota 11).

17. Idem, fol. 21: «Tres paños para paredes de alcoba, adornados de bordados de oro, compuestos de muchos colores, cada uno de ellos de dieciocho palmos en cuadro, con cuatro columnas de bordado relevado de oro en cada uno, que sostienen una pérgola sobre la cual hay diversos pájaros del natural en bajo relieve bordados de seda de muchos colores, y al fondo de esa pérgola, paisajes en lontananza y más cerca, colinas con hierba, y flores encima, y pájaros que vuelan, y en cada uno de ellos tres alfombras de bordado de oro con flores tomadas del natural, y en uno un león encadenado, en el otro un oso que despedaza un perro y en el otro un tigre encadenado, con una balaustrada de oro en cada uno» (traducción del autor).

18. SÁnchez Amores, Juliana: op. cit., p. 177, siguiendo inventarios del Museo, indicó que la medida de los paños era 4,77 m de alto por 4,06 de ancho, salvo las dos más estrechas, para las que dio una medida de ancho de 2,31 m. Sin embargo, los paños grandes son prácticamente cuadrados, por lo que hemos medido su anchura, que está en torno a los 4,60 m de media. Esto concuerda con los inventarios de Nápoles; el palmo napolitano medía $26,367 \mathrm{~cm}$.

19. Puede tratarse de un guepardo por ser el único gran felino presente, aunque encadenado, en ámbitos domésticos de personajes de gran alcurnia.

20. Por las razones que explicaremos, es el que está agachado y tiene la cabeza entre las patas. 


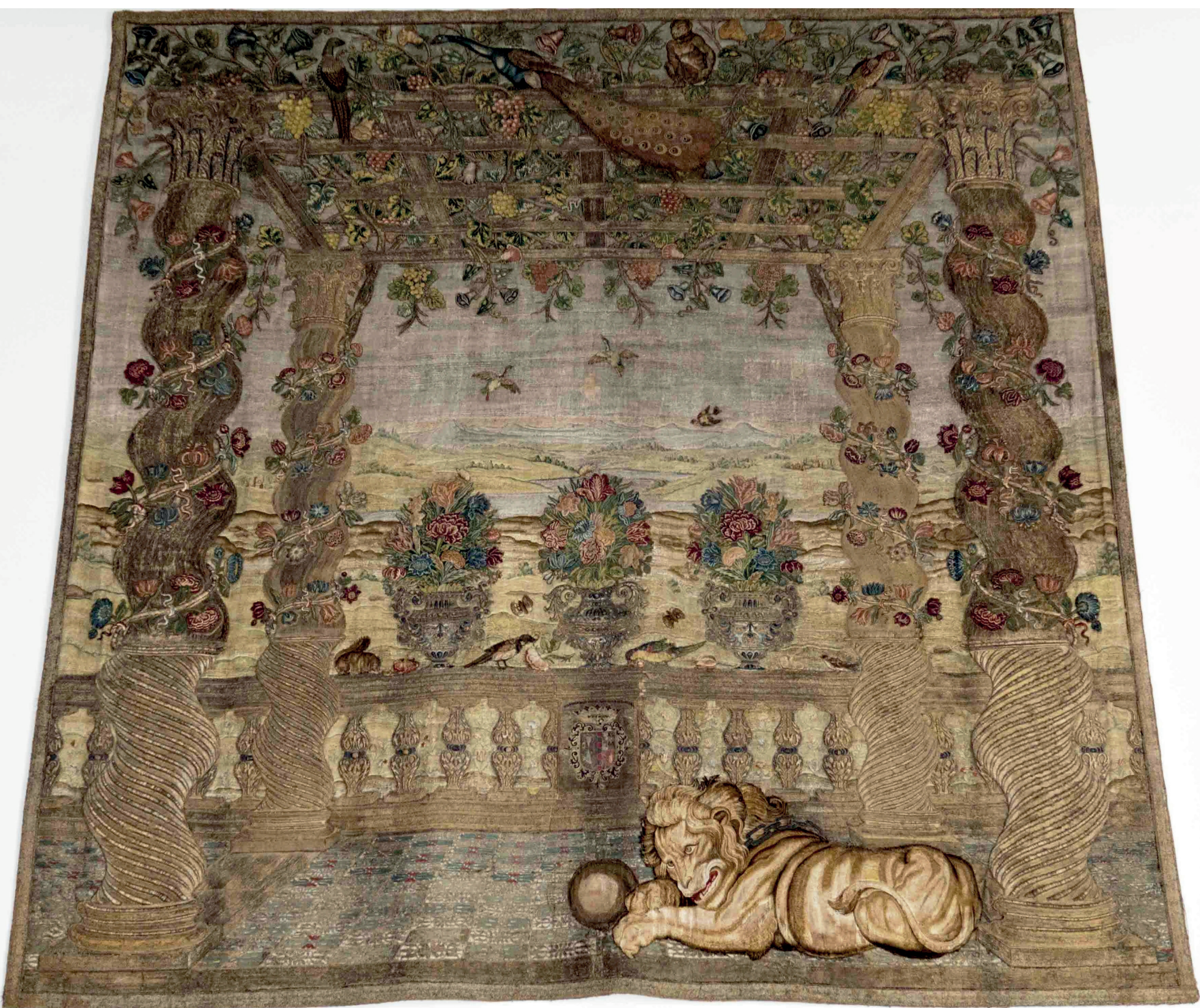

FIGURA 3. PAÑO DEL LEÓN CON BOLA

Madrid, Museo Arqueológico Nacional, n. ${ }^{\circ}$ inv. 52690. 
Tre panni di racamo di seta historiati con figure diverse rappresentanti la nascità d'Achille, che comprendono figure d'huomini, fra quali un Ré sotto baldachino, centauri, e figure diverse di donne co'paesi lontani, e vicini, con fiori, herbe, arbori e frutti diverse, et in uno una Marina co' Nettuno con carro, e mostri marini, e uscelli da remo, uno largo palmi vent'uno alto sedici, l'altro largo venti alto sedici, e l'altro largo dodici alto sedici, et in molti luoghi d'essi panni co'racamo d'oro, qualli stani in mano alla signora Fulvia [Picchione] ${ }^{21}$.

Esta colgadura, de paños bordados algo más grandes que los anteriores, tenía asuntos mitológicos relativos a Aquiles ${ }^{22}$. La composición tampoco parece semejante. Nada sabemos de lo sucedido con estos tres paños.

En I644 cesó Medina de las Torres en su virreinato, y en mayo de ese año, los esposos partieron para su palacio de Chiaia, donde quedó Anna esperando el parto de su último hijo, Domingo, mientras el duque emprendía en julio el viaje a Madrid acompañado de un voluminoso cargamento reseñado en el correspondiente inventario $^{23}$. Con él se iniciaba la serie de envíos de objetos artísticos de su guardarropa desde Nápoles a Madrid, que no finalizó hasta I656.

El 24 de octubre de I644 murió Anna Caraffa en Portici, y al año siguiente, su hijo, ya príncipe de Stigliano, salía de Nápoles para reunirse con su padre, acompañado de su correspondiente equipaje de objetos artísticos que quedó también inventariado. Un nuevo cargamento salió hacia España en I649 24 , y, por fin, en I655, ante la cercanía de la boda del primogénito de los duques, Nicolás, su abuela, Elena Aldobrandini, duquesa de Rocca di Mondragone, realizó un envío muy voluminoso de ropas y plata.

El inventario de este año da testimonio de que en esa remesa venía la colgadura de los animales, así descrita por el mayordomo Giovanni Petorino ${ }^{25}$ :

21. Idem, fol. 22 v. «Tres paños de bordado de seda historiados con figuras diversas que representan el nacimiento de Aquiles, con varias figuras de hombres, entre los cuales un rey bajo baldaquino, centauros y figuras diversas de mujeres con paisajes lejanos y cercanos, con flores, hierbas, pájaros en los remos, uno con veintiún palmos de largo y dieciséis de alto, el otro con veinte de largo y dieciséis de alto y el otro con doce de largo y dieciséis de alto, en muchos lugares de los paños con bordados en oro, que están en manos de la señora Fulvia [Picchioni]» (traducción del autor).

22. Los paños bordados napolitanos tienen en general figuras humanas; de animales solo tenemos noticia de ésta.

23. AHN, Consejos Suprimidos, leg. 51182/1/1. Guardarobba del 1644; Nota di tutta la robba, che e stata consegnata a Giovanni Pettorino Guardarobba di Strada dell'Eccmo Sigre Duca de Medina per il Viaggio di Spagna per mano di Alessandro Bechi Guardarobba Maggre di S. E. in presenza del Sigre Fra D. Isidoro d'Argaio Magiordomo per il viaggio hoggi alli 25 luglio 1644 nel Reg. Castelnovo di Nap.; Nota della robba ritornata da Spagna et reconsegnata da Gio. Bettorina al Sr Alessandro becchi per ordine dell'Eccma Sgra Duchessa di Mondragone.

24. AHN, Consejos Suprimidos, leg. 51182/1/2. Guardarobba del viaggio del Principe mio sre nel 1645; Nota di tutta la robba consegnata a Giovanni Pettorino; Guardarobba del'Eccmo Sgr Prencipe di Stigliano a po di Maggio 1649 in presenza di d. Matteo Paris nel Regio Castello novo di Nap. etc.; Robbe consignate aFrancesco Aquino per servitio della Reccamera di detto Eccmo Sgr Prencipe nella medem giornata et anno ut supra; Argenti consegnato a Gio Bettorino Guardarobba dell Ecca di Stigliano; A 24 gennaio 1649 Libri incasciati per Spagna coperti di cordovana rossa co'arme et imprese stampate d'oro in cascie conforme li numeri dell'in margine; Panni di razza leuati per Spagna da Gio. Pettorino; Nota di quello c'e inviato in Spagna dall'Eccma Sigra Duchessa di Mondragone per seruitio dell'Eccmi Sigr Duca di Medina las Torres et sgre Pnpe di Stigliano a 8 di luglio 1649 co'le galere; Nota delle robbe della recammera dell'Eccmo Sigr duca di Medina las Torres consígnate a Francesco d'Aquino; Robbe consígnate a Franco d'Aquino per Spagna.

25. AHN, Consejos Suprimidos, leg. 51182/1/3. Guardarobba del 1655; A di 20 di Maggio 1655 Inventario di Robbe consignate a Giovanni Petorino; Cascie inuiate in Spagna a carrico d'Alonso Peralta nel vascello chiamato San Giorgio 


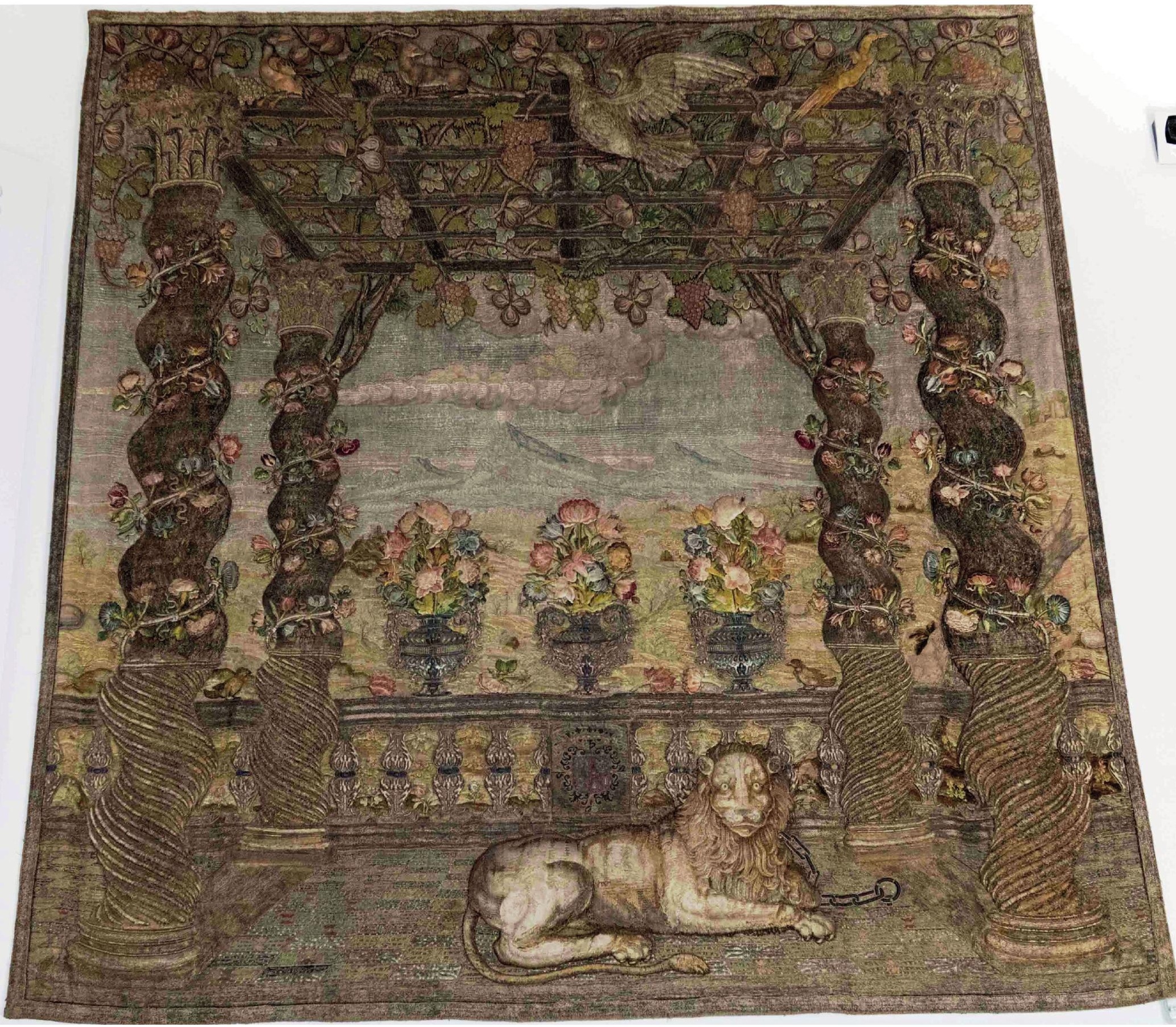

FIGURA 4. PAÑO DEL LEÓN ERGUIDO

Madrid, Museo Arqueológico Nacional, n. ${ }^{\circ}$ inv. 52699. 
1655, 20 mayo. Inv. robbe Giovanni Petorino. - In primis Panni sette grande bordati ricchi alti et larghi palmi deced'otto foderati di tela di casa, due panni più piccoli per le quinte della medemi altezza, et larghi palmi otto in circa, e detto racamo rapresenta una pergola sostentata da colonne d'oro di relevo co'ucelli al naturale, pigne d'una, et alti frutti recamati d'oro, et seta di piú colori co'una balagurhata, et sopra lei di racamo d'oro con fiori di seta al naturale di basso relievo, et à ciascun panno un animale racamato di seta al naturale, cioé uno co'una tigre, dui co'leoni, uno con cervo, uno co'anticervo, uno co'cane, un altro co'orso, che sbrana un cane, et due piccoli con cagnolo et scimia, et tutti guarniti in torno con histori d'oro et racamo, et a ciascun panno arravogliato co'cortina di tela bianca in una colonna, et cassa [...] Dette due partite [la otra partida estaba compuesta de telas de Florencia y 20 sillas] condotte da Alonso Peralta a 31 di maggio 1655 . Giovanni Petorino ${ }^{26}$.

La colgadura de los animales había aumentado con seis paños respecto a la descrita en el inventario de I64I, cuatro de ellos con las mismas medidas que los antiguos, y otros dos más estrechos - ocho palmos- descritos todos con una composición similar: pérgola con columnas y balaustrada, decoradas con pájaros y frutas y delante un animal, añadiendo a los tres de I64I, otro león (FIGURA 4), un lebrel (FIGURA 5), un ciervo (FIGURA 6) y un carnero (FIGURA 7) en los grandes y un perrillo (Figura 8) y un mono (Figura 9) en los estrechos. Se anota también que se enviaron a Madrid al cuidado de Alonso Peralta el 3I de mayo de i655, enrollados en una columna y envueltos en tela blanca, metidos en una caja ${ }^{27}$. El examen detenido de los paños pone de relieve alguna ligera diferencia entre los primeros - con pantera, león con la cabeza entre las patas y oso despedazando un perro-y los posteriores, y es la presencia, en los más antiguos, de algunos pájaros que surcan con su vuelo el paisaje, mientras los otros seis no los tienen.

il Grande del Capitan Curle de Silvestre di Nation Olandese. S'imbarco a 31 di Maggio 1655; Inuentario delle gioie che mi Sigra la Duchessa di Mondragone inuia all'Eccmo Principe di Stigliano mio signore e suo nepote a rechista di S.E. che si consegnano al Capitan D. Domenico Mongu Gentil'huomo di Camera di detto eccmo Sigre a 27 di giugno 1655; Nota d 'argenti cioe robba per disfare dati al sigr Marcantonio Mondragone argentiero; A 25 di Maggio 1656 Argenti portati a Chiaia dal Guardarobba Jacouo Almeriggi della Sigra Eccma Duchessa di Mondragone notati da d. Matteo Paris; Nota de quadri et altri robbe per orde di S.E. Pra inuiati co'Paolo Salomone a 4 Giugno 1656; Argenti consignati a Jacouo Almeriggi guardarobba dalla Sra. Lucia Bonghi per ordine dell'eccma sigra Duchessa di Mondragone a 29 Maggio 1656; Colli che uanno in Spagna leuati dalla Guardarobba del Sigr Principe de Stigliano mio Sigre sopra il Vascello chiamato Sansone consignati al Alfiero Diego di Borgia a 18 di Marzo 1656; Nota delli colli leuati dal signre d. Domco Morgu a 30 di gennario 1656 inbarcati sopra la tartana notata dal v. Duca del Infantado co'intervento del sr D Paulo de fabritijs e sr. d. Giulio Baratuccio.

26. Idem, fol. 1 «1655. 20 de mayo. Inventario del guardarropa Giovanni Petorino. En primer lugar, siete paños grandes bordados ricos, con dieciocho palmos de alto y largo forrados de tela casera, dos paños más pequeños de la misma altura y de ocho palmos de largo poco más o menos, y el dicho bordado representa una pérgola sostenida de columnas de oro de relieve con pájaros del natural y racimos y otras frutas bordadas de oro y seda de muchos colores con una balaustrada y sobre ella, bordados en oro con flores de seda natural de bajo relieve, y en cada paño un animal recamado de seda al natural, que son: uno con un tigre, dos con leones, uno con ciervo, uno con carnero, uno con perro, otro con oso que despedaza a un perro y dos pequeños con perrillo y mono, todos ellos guarnecidos alrededor con historias en oro y bordado y cada uno de los paños enrollado en una cortina de tela blanca y una columna y en una caja [...] Estas dos partidas, conducidas por Alonso de Peralta a 31 de mayo 1655. Giovanni Petorino» (traducción del autor).

27. En los dos paños estrechos no existe templete, sino dos columnas unidas por colgantes de hojas y frutos a modo de dintel. 


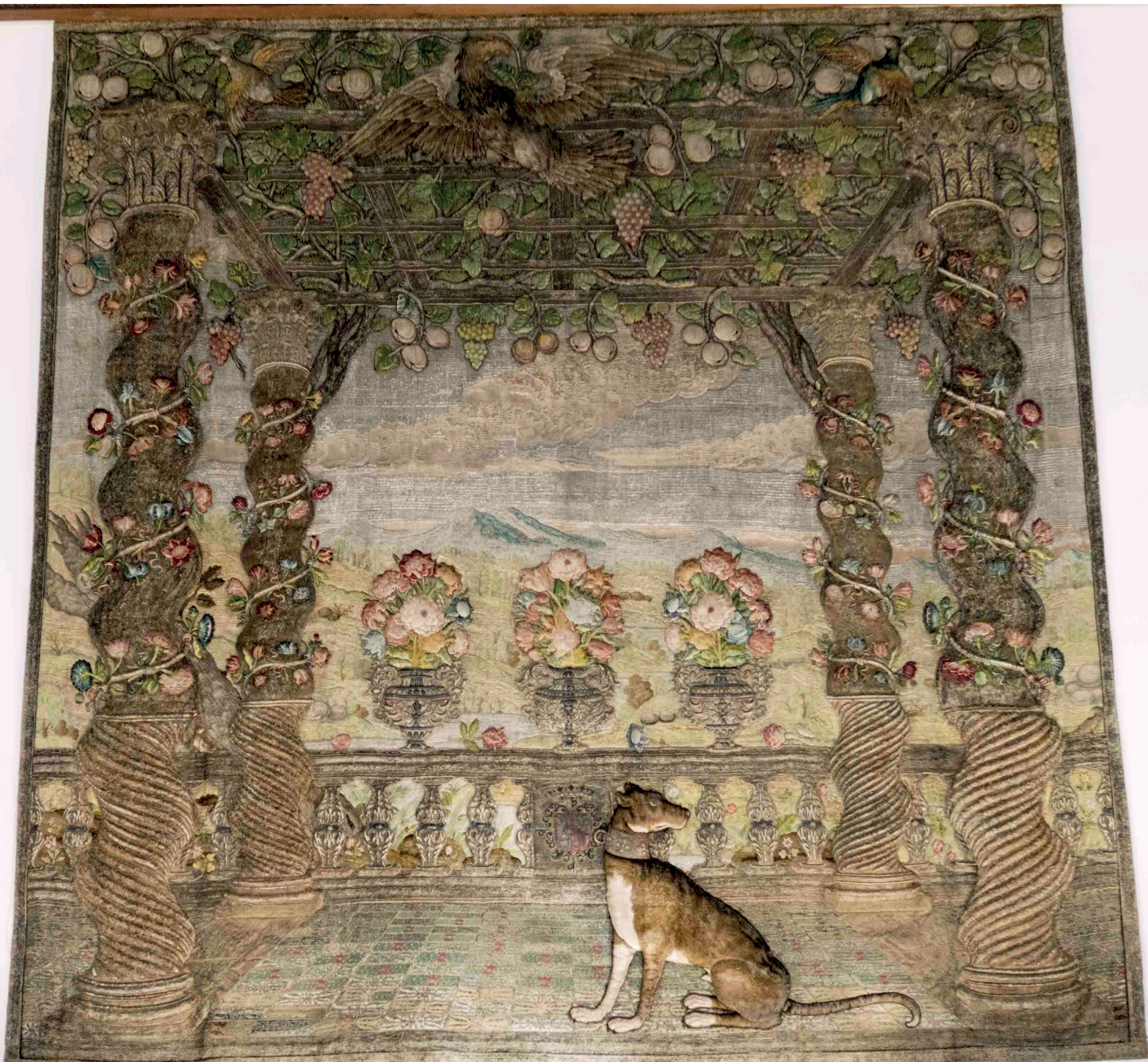

FIGURA 5. PAÑO DEL LEBREL

Madrid, Museo Arqueológico Nacional, n.․ inv. 52653 
Pocos meses después, la colgadura se hallaba en Madrid. Ha sido repetidamente citada en publicaciones la noticia incluida en los Avisos de Jerónimo de Barrionuevo, quien fechó en 6 de octubre de I 655 el siguiente acontecimiento:

Todos estos días han entrado las alhajas y recámara del Príncipe de Astillano en carros; la plata, colgadura y joyas han llegado en 30 cajones, 3 coches, uno forrado de plata la madera, bordado sobre carmesí de lo mismo; otro verde y otro azul, y 3 tiros de 7 caballos napolitanos se esperan. Dícese montará más de un millón, por haber querido echar el agüela [sic] el resto en estas bodas con la Casa de Alba ${ }^{28}$.

Se equivocó Barrionuevo al asignar los bienes a la recámara del príncipe, que ni había tenido casa, ni la tuvo hasta I657 en que su compromiso matrimonial con María Álvarez de Toledo concluyó en esponsales. Los cajones, y en ellos la colgadura, llegaron a la casa del duque de Medina de las Torres, situada cerca de los Premostratenses, y luego se llevó aquélla con el resto de su ajuar al palacio de los Oñates tras casar en I658 con su tercera mujer, doña Catalina Vélez Ladrón de Guevara, condesa de Oñate y Villamediana. En I657, Baltasar Gracián publicó la tercera parte de su Criticón, donde ensalzaba estas colgaduras comparándolas con las de la esposa, diciendo: «¿qué tienen que ver con ellas las más ricas, y bordadas del célebre duque de Medina de las Torres?» ${ }^{29}$.

Mucho más explícito y determinante es el valioso testimonio de Lodewijck Huygens $^{30}$, integrante de la embajada extraordinaria enviada por los Estados Generales de las Provincias Unidas en I660-I66I, primera tras la paz de Westfalia de I648. Según esta fuente, no utilizada al respecto hasta ahora, el I7 de marzo de I66I visitaron Huygens y sus compañeros el palacio de los condes de Oñate en la calle Mayor, donde residía el duque de Medina de las Torres. El holandés anotó:

Después nos llevaron por un gran número de otras estancias, todas ellas repletas de tapices. Sin embargo, el más valioso de todos se conservaba arriba, con varios otros muebles, en un almacén. Había costado 100.000 reales de a ocho y la mayoría reconocía no haber visto nada igual en ninguna parte. El tapiz representa una serie de paisajes en seda que se entrevén a lo lejos por entre unas columnas que llevan incorporados unos ornamentos arquitectónicos bordados en oro. Los bordados tienen tal grosor que parecen bajorrelieves. Arriba hay pájaros de todo tipo y abajo se ven unos animales en seda muy bien trabajados. Hay 36 sillas que hacen juego con el tapiz, así como un dosel, también extraordinariamente valioso, y unos cojines para colocar encima de un estrado... Sin embargo, aquella gran tapicería provenía de Nápoles, donde, según

28. Barrionuevo de Peralta, Jerónimo: Avisos (1654-1658). Madrid, 1892, t. II, p. 153. Mas noticias de este autor, con cantidades irreales, en 1656 (t. II, p. 288, y t. III, pp. 9 y 10). Da 17 años para su hechura, excesivos y coincidentes con los pasados desde la llegada del Virrey a Nápoles.

29. Gracián, Baltasar: El Criticón. Tercera parte, Madrid, Pablo del Val, 1657 (ed. Amberes, Geronymo y luan Baptista Verdussen, 1669), p. 278.

30. Agradezco esta referencia a Rocío González Chaves. 


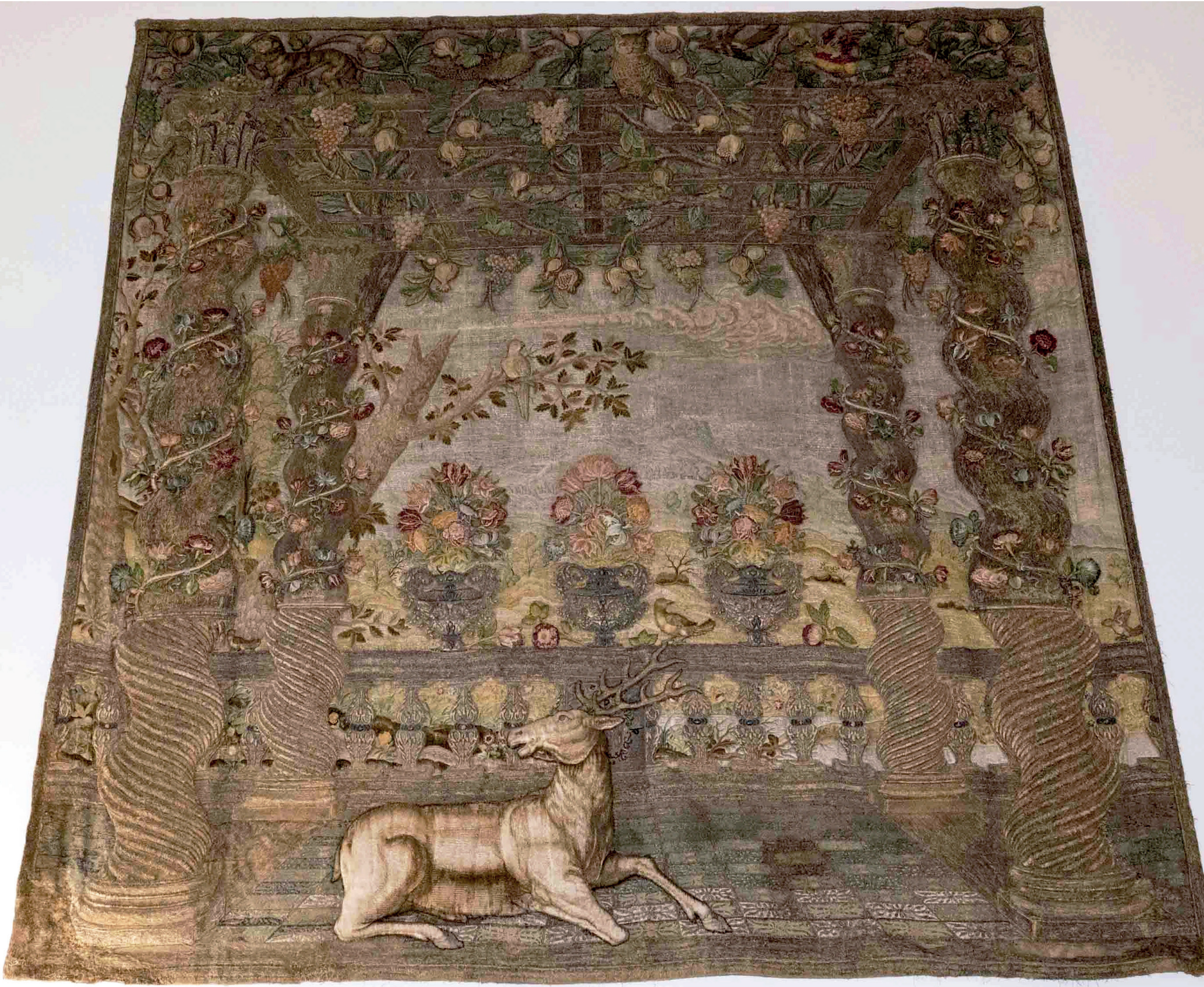

FIGURA 6. PAÑO DEL CIERVO

Madrid, Museo Arqueológico Nacional, n. ${ }^{\circ}$ inv. 52632. 
creo, el duque había sido virrey y contrajo matrimonio con la princesa de Stigliano, su segunda esposa ${ }^{31}$.

Los holandeses habían llegado a Madrid pocos días antes del final de i66o y la legación visitó los palacios reales, pero ninguna de sus riquezas, ni otras que vieron en la Villa, mereció un comentario más extenso que el dedicado a esta colgadura ${ }^{32}$, con la que cerró el autor su relación, a pesar de que aún permanecieron en Madrid dos meses y medio más. No ha de extrañar que la visitaran en un almacén de la casa, pues era invierno, estación en que las paredes de las grandes casas se cubrían con tapices, que permitían conservar mejor el calor, mientras los paños bordados y guadamecíes eran revestimientos parietales típicos del verano.

Los documentos examinados hasta ahora nos permiten afirmar que esta colgadura se hizo en Nápoles, probablemente iniciada hacia I640 o poco antes, concluidos los tres primeros paños en I64I y, deducimos, ya completa en I644, pues no es probable que Medina de las Torres siguiera haciendo encargos en Nápoles tras su marcha. La aparición progresiva de los paños en los inventarios y la particularidad de sus asuntos apuntan a un encargo del duque que se hizo, según sus gustos, por un solo obrador napolitano. No es fácil concluir si fueron encargados primero tres paños y después los otros seis o si el encargo fue único, puesto que la importante labor que encerraban haría que su conclusión se prolongara en el tiempo. La legación holandesa certifica su origen napolitano, que habrían conocido por manifestaciones del duque. No nos cabe duda de que la investigación de especialistas en Nápoles llegará a desvelar el nombre del bordador o bordadores de esta colgadura, su precio y fechas exactas en que se llevó a cabo la labor ${ }^{33}$. Entre tanto, nuestra aportación avanza estas noticias contenidas en documentos conservados en España. Los que damos a conocer a continuación dan cuenta de lo sucedido con esta obra en los años que transcurren entre su llegada a Madrid y su paso al convento de Santa Teresa.

El duque de Medina de las Torres murió en i 668 y sus bienes fueron evaluados en la testamentaría. Los bordadores Francisco Dávila y Bernardo Fajardo tasaron la colgadura en II de noviembre de i669. La partida señala:

217. Nueve paños. Primeramente nueve paños de colgadura rica de matizes de sedas y rreliebes de oro realzados con diferentes pájaros, abes y animales, y un dosel con armas en el zielo y quatro pedazos de frisos grandes, que en todo son quinze piezas, todo bordado de oro realzado y rrico, en ochozientos y setenta y siete mil y ochozientos reales de vellón. $877.800^{34}$.

31. Huygens, Lodewijck, (ed. EbBen, Maurits): Un holandés en la España de Felipe Iv: diario del viaje de Lodewijck Huygens (1660-1661). Madrid, Editorial Doce Calles, 2010, pp. 228-229.

32. Lo cual es muy sintomático, habida cuenta de la riqueza de los tapices que conocerían de los Países Bajos. 33. La doctora Maria Rosaria Mancino me hizo saber amablemente que había encontrado documentación en Nápoles sobre la hechura de la colgadura; esperamos que publique próximamente su estudio.

34. Archivo Histórico de Protocolos de Madrid (AHPM), prot. 8181, fol. 410v.-411r. 
A los paños napolitanos se había añadido una nueva pieza con función de dosel, compuesta del respaldo, cielo y cuatro frisos ${ }^{35}$, que debió ser obra madrileña entre I 655 y $166 \mathrm{o}^{36}$. El precio se fijó por los tasadores conjuntamente para las quince piezas en 877.800 reales, 79.800 ducados, verdaderamente alto, incluso comparado con el de las más excelentes tapicerías de Flandes. A pesar de lo cual y contra lo que solía ser costumbre, el duque no la vinculó a su mayorazgo.

El 22 de diciembre de I672, el príncipe de Stigliano presentó una súplica ante el teniente de corregidor de Madrid para que se le entregara esta colgadura ${ }^{37}$. Tras fallecer su padre, los paños habían quedado en la casa de la tercera esposa del duque de Medina de las Torres, pero pasaron a un depositario judicial mientras se solventaban los pleitos sobre la herencia del difunto. En la súplica, Stigliano afirmó que le pertenecían como quedaría demostrado, pero que solo pedía el levantamiento del depósito para repararlos antes de que el maltrato que habían sufrido provocara su pérdida definitiva y con ello un perjuicio para sus bienes, que estimaba en 80000 ducados, el mismo valor que le dieron los tasadores en i669. El auto del teniente de corregidor Juan Lucas Cortés estimó la solicitud y ordenó que, una vez aderezada la colgadura, se devolviera a su depósito sin que el príncipe la utilizara en su servicio, y dio también libramiento y despacho para que el depositario, Juan de Santiago, mercader de sedas de la Puerta de Guadalajara, le entregara la colgadura. Al día siguiente formalizó don Nicolás la obligación que exigía el auto, compareciendo en calidad de testigos dos de sus criados, y también dio carta de pago a favor del mercader por la entrega del depósito.

La colgadura se describe en el documento:

Los canpos y cuerpo de todos los paños en bordados de matizes de sedas en forma de país con unas colunas salomónicas a los lados de oro de medio relieve, enlazadas diferentes flores bordadas de matizes, y en la parte de abajo un enladrillado que cierra una barandilla, tanbién de oro, y al pie de ella en cada paño un animal de medio relieve, diferentes jéneros bordados también de matizes de sedas, y en todos los dichos paños y dosel ay un escudo de las armas de su excelencia.

La única novedad de esta descripción es la alusión a los escudos de armas, que, a nuestro entender, fueron añadidos a los paños después de su llegada a Madrid, probablemente al tiempo que se hacía el dosel y los frisos, que también los llevaban, sin duda mucho más destacados. Los de los nueve paños son muy pequeños y se hallan en uno de los balaustres que cierran el templete. En tres de ellos, el animal ocupa con su cabeza la parte central de la barandilla, de modo que apenas se adivina un pequeño fragmento del escudete; a nuestro juicio, es un indicio claro de que

35. La tasación realizada en 1689 (VIGNAU y BALLESTER, Vicente: op. cit., pp. 47-48) indica que el dosel media 122 varas en cuadro, mientras que los paños en su conjunto tenían 48 varas cuadradas. Probablemente, el tipo de labor bordada en el dosel no era la misma que la de los paños.

36. Recordemos que esta pieza ya había sido mencionada por Huygens, al igual que las sillas, que también se hicieron por tanto en Madrid.

37. Vid. APÉNDICE DOCUMENTAL. 


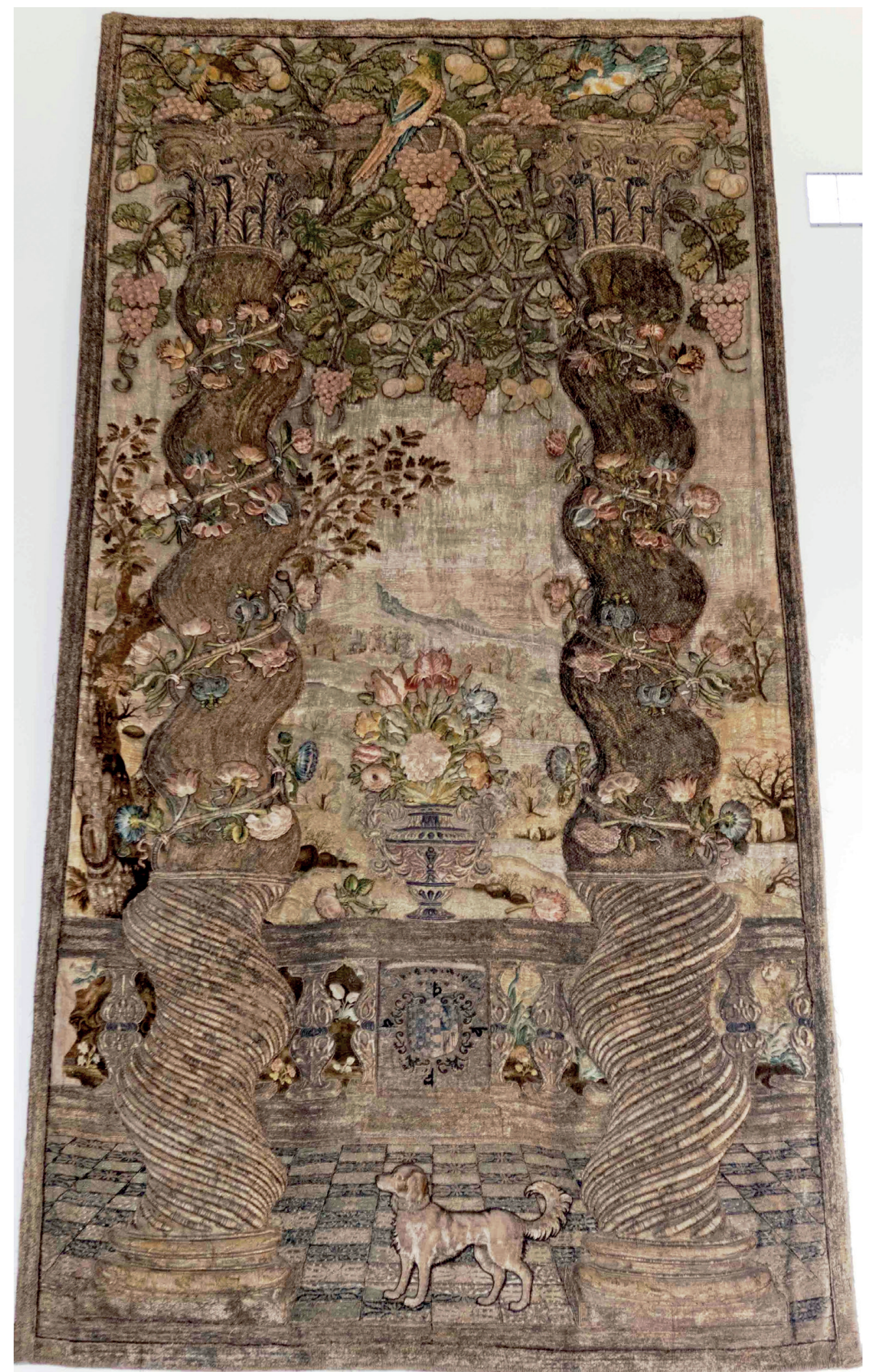

FIGURA 8. PAÑo DEL PERRILLO

Madrid, Museo Arqueológico Nacional, n. ${ }^{\circ}$ inv. 52674. 
no existían originalmente. Quizá Medina de las Torres pensara en vincularla a su mayorazgo y por ello hizo bordar los escudos de Guzmanes y Carafas, que eran los del príncipe de Stigliano, primer titular del vínculo, y no los suyos.

Once años después de este suceso, dispusieron don Nicolás y su esposa, María Álvarez de Toledo, la fundación del convento madrileño de Santa Teresa de carmelitas descalzas ${ }^{38}$. El príncipe solicitó y obtuvo del rey en 28 de diciembre de 1683 la facultad de tomar unos juros adscritos al mayorazgo de su casa cuya renta era de 4700 ducados anuales para dotar al convento, a condición de que vinieran a dicho mayorazgo el patronato del convento y la colgadura rica. Se le daba la opción de restituir al mayorazgo en cuatro años las cantidades tomadas, en cuyo caso no tendría efecto la vinculación del patronato y la colgadura.

Stigliano había tomado préstamos de Vincenzo Giustiniani para poder reintegrar los juros al mayorazgo, dejando la colgadura en prenda: poco antes de morir, el 29 de noviembre de I688, había otorgado escritura de donación al convento con libre facultad de las carmelitas para que pudieran incluso venderla si fuera preciso para ayuda de su nueva fábrica. Declara expresamente que la colgadura no estaba vinculada y que había estado empeñada en casa de Giustiniani, donde las monjas tenían que recogerla, dando a entender que había saldado su deuda por el préstamo. Los paños seguían en poder del banquero el 7 de enero de I689, fecha de la muerte del príncipe. Hicieron falta múltiples diligencias para recuperarlos, pues el prestamista los tenía embalados en casa del marqués de Serra, genovés, que trataba de llevárselos de Madrid. Gabriel de Henares, representante del convento, elevó el I2 de febrero de i689 una petición al visitador eclesiástico para que impidiera la salida de la colgadura. Se hizo información, y los testigos confirmaron que el príncipe de Stigliano había tratado de recuperarla para el convento, pero que Giustiniani la había dejado en casa de Serra con intención de enviarla a Génova. El visitador ordenó el embargo de la colgadura y su depósito en el presbítero don Antonio de la Fuente, y finalmente se entregó al convento el 4 de mayo de dicho año. Los bordadores Francisco de Salas y Francisco Espiguel la tasaron el 30 de agosto siguiente en 329.200 reales de vellón (29.927 ducados y 8 reales), menos de la mitad del valor de su tasación en $1669^{39}$.

38. Vignau y Ballester, Vicente: op. cit., pp. 31-33.

39. Los acontecimientos de 1689 descritos derivan de la documentación dada a conocer por ldem, pp. 36-47. Los precios en que fueron valorados fluctuaron sin ostensibles diferencias, salvo el de 1689 . Huygens recibió la noticia de que costaron 800.000 reales. En 1672 el príncipe aumentó algo su valor, a 880.000 reales, y dieciséis años más tarde a 1.030.200 reales de vellón. Sin embargo, la tasación de los bordadores de 1689 fue muy inferior, pues no llegaba a 330.000 reales incluyendo el dosel, menos de la mitad de la más baja dada por los propietarios. La explicación puede residir en el deterioro que habían sufrido las piezas desde su fabricación medio siglo antes y de la que queda el testimonio de 1672 . El deterioro de la colgadura fue progresivo tras la estancia en el convento y en el Museo, donde se ha limpiado recientemente. 


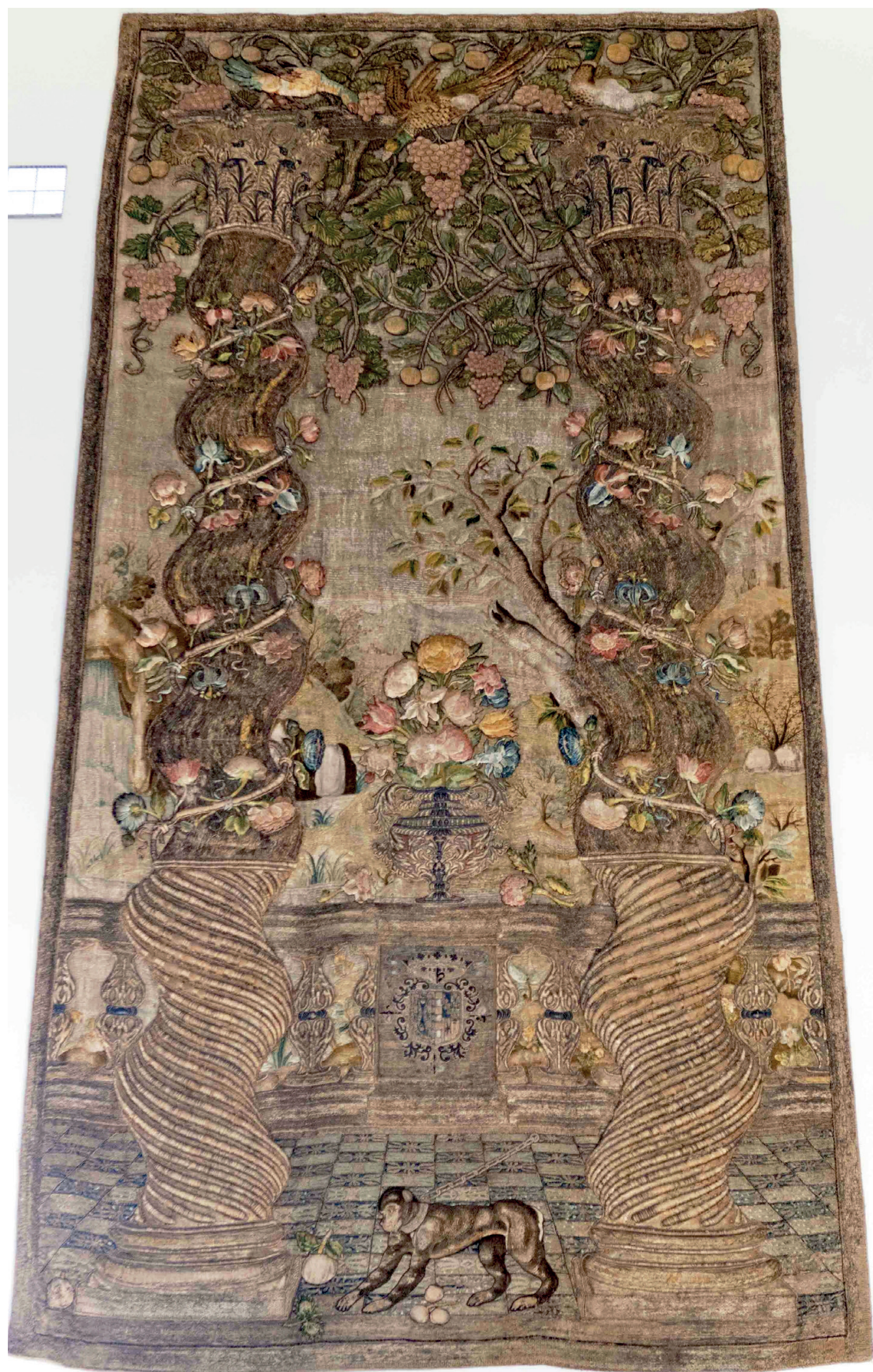

FIGURA 9. PAÑO DEL MONO

Madrid, Museo Arqueológico Nacional, n. ${ }^{\circ}$ inv. 52675. 


\section{CUESTIONES ESTILÍSTICAS E ICONOGRÁFICAS}

Existe un único ejemplar conocido de colgadura que presente similitudes con la del Arqueológico desde un punto de vista técnico y estilístico, y es, aunque incompleta, la compuesta por los seis paños de seda bordada - que fueron diez originariamente-que se conservan en la catedral de Santiago, que la recibió como regalo de Felipe IV en I $655^{40}$. Aunque el Rey fue el donante, no es probable que fuera su comitente, y la debió de obtener como obsequio del virrey de Nápoles, el conde de Monterrey (I63I-I637), el propio duque de Medina de las Torres, el Almirante de Castilla (I644-I646) o el conde de Oñate (I648-I653) ${ }^{41}$. Coinciden las pérgolas de columnas salomónicas con tercio inferior de estrías helicoidales, la barandilla del segundo plano, los fruteros, el suelo de baldosas ajedrezadas y el fondo de paisaje. Incluso los paños más estrechos tienen dos columnas y no cuatro, por lo que las hojas y frutos no forman un templete, sino un dintel, tal como ocurre en la colgadura de Medina de las Torres. Sólo hay ligeras variantes en su menor altura y aspectos decorativos: los paños del Museo rematan en un emparrado con plantas y animales, y en Compostela lo hacen en un entablamento corintio del que penden festones y guirnaldas y la balaustrada en la serie de la Catedral aparece a los lados de la pérgola y no cerrándola como en la madrileña. Las similitudes entre ambas colgaduras son tan grandes que opinamos que ambas salieron del mismo obrador napolitano.

La colgadura compostelana dispone bajo las pérgolas cinco representaciones de las Edades del Hombre según Hesíodo, aunque las imágenes están inspiradas en grabados de las Metamorfosis de Ovidio: niños danzando para representar la Edad de Oro, adultos que aluden a las estaciones del año en la Edad de Plata, trabajadores de piezas de metal para representar la Edad de Bronce y luchadores y mujer desesperada para la Edad de Hierro. Por fin, la Edad de los Héroes utiliza distinta fuente iconográfica y se sirve de la escena del ataque de Fineo a Perseo en su boda con Andrómeda, que éste detiene petrificando a aquél y a sus secuaces. El título que la identifica es Perseo disturbato escrito en italiano ${ }^{42}$. Los paños estrechos no llevan escenas, sino solo bajorrelieves alegóricos en las basas de las columnas. La figuración abundante, frente a la presencia de un único animal en los ejemplares del Arqueológico, no modifica el concepto estructural de la colgadura, pues es tan importante la presencia de las columnas y templetes con paisajes al fondo, que la presencia humana o animal pierde importancia frente a la función de estos paños, que era la de prolongar visualmente un paramento, con un efecto de amplitud espacial infinito.

La descripción contenida en el inventario de los bienes de Carlos II de $\mathrm{I} \mathrm{OI}^{43}$ permite conocer el aspecto de una desaparecida colgadura de seda, oro, plata y coral,

40. Los paños grandes miden $4 \times 4 \mathrm{~m}$ (uno de ellos está actualmente cortado) y los pequeños $4 \times 2,5 \mathrm{~m}$.

41. Agradezco a la doctora Manuela Sáez que me haya comunicado su estudio de ciertas telas bordadas, que considera napolitanas, pertenecientes al convento de Santa Clara en Monforte de Lemos, fundación del conde de Lemos, virrey de Nápoles.

42. Taín Guzmán, Miguel: op. cit., p. 154.

43. Fernández Baytón, Gloria: Inventarios reales. Testamentaría del rey Carlos II. Madrid, Museo del Prado, 1975, t. I, pp. 279-280. Los precios de los figurados oscilaban entre 52.000 y 58.000 reales, mientras que el primero 
que, pese a su origen siciliano, debió tener una cierta semejanza con las anteriores, al menos en su función de crear ilusión visual de espacio exterior. Los seis paños fueron encargados por don Juan José de Austria en Palermo entre I648 y I65I, años en que ocupó el virreinato de la isla. Combinaba tres ejemplares con escenas mitológicas y otros tres «con jarras», lo que confirma que la figuración humana, vegetal o animal era una alternativa de importancia secundaria en este estilo de colgaduras. En las descripciones de todos los paños aparecen perspectivas, bien arquitectónicas o arbóreas a modo de corredores, jarrones de flores y pájaros. Tres de ellas describen historias: Orfeo al pie de un árbol rodeado por animales, Jezabel arrojada por el balcón, y un palacio en perspectiva con una ninfa encima de una fuente y unos tritones y Faetón en lo alto; los otros tres paños, sin escenas, ofrecían la misma disposición perspectiva, con corredores vegetales adornados con fuentes, jarrones, ánades y pájaros y remate de jarrones coronados. Pilar Benito García ${ }^{44}$ y Elvira González Asenjo ${ }^{45}$ han llamado la atención sobre esta rica serie hecha para el nacimiento de la infanta Margarita de Austria y que se empleó en su bautizo.

En Sicilia se conservan algunos ejemplares de colgaduras que recuerdan la descrita en el inventario de Carlos II. Los dos paños del convento de Santa Maria della Concezione de Siracusa, actualmente en el tesoro del Duomo ${ }^{46}$, aunque datados en el primer cuarto del siglo xvin, entroncan con los regalados a Felipe Iv por don Juan José de Austria: uno presenta una galería de finas columnas salomónicas en el primer piso y cariátides en el segundo, que se prolonga hasta un fondo de paisaje marino, y en primer término un jardín limitado por balaustradas a los dos lados con grandes jarrones florales que dejan espacio para una placeta con una hermosa fuente polilobulada; en el camino aparecen pavos reales en disposición simétrica. El otro muestra una perspectiva palaciega claramente inspirada en diseños del arte efímero y se la relaciona con el aparato decorativo de la entrada de Felipe v en

y el tercero de los ornamentales fueron tasados en 87.500 y 65.000 reales, lo que resulta paradójico salvo que interpretemos que la labor de flora y fauna era muy compleja. La serie se completaba con otros elementos, como doce piernas, de cinco anas de caída pero sólo uno de ancho, tasada cada una en 11.000 reales, con dibujo de enlazados, y tres cenefas que hacían de friso a los paños. En total importó la colgadura 57.1125 reales de vellón, unos 300.000 reales menos que la del Príncipe de Stigliano.

44. Benito García, Pilar: «El Alcázar vestido de seda: colgaduras y alfombras de S.M.C. Carlos II» en CHECA CREMADES, Fernando (coord.): El Real Alcázar de Madrid: dos siglos de arquitectura y coleccionismo en la corte de los reyes de España, Madrid, Comunidad de Madrid, 1994, pp. 310-311. Citó también entre los bienes de Carlos II otra colgadura rica de coral que fue valorada en 1.028.960 reales de vellón, es decir, prácticamente el mismo precio que la estimación que hizo don Nicolás de Guzmán de 1689 de la suya, tal vez por no haber sufrido daños. Fue regalada a la Corona por la duquesa del Infantado, doña Catalina Gómez de Sandoval y Mendoza (1616-1686), que heredó el título de su hermano don Rodrigo, fallecido en 1657. Precisamente fue éste el sucesor de don Juan José de Austria como virrey de Sicilia (1651-1655). Medían cinco anas (3,47 m) de caída y de tres a tres y media $(2,08 \mathrm{~m} \mathrm{2,43} \mathrm{m})$ de ancho (vid. Fernández BAYTón, Gloria, op. cit., pp. 282-283).

45. González Asenjo, Elvira: Don Juan José de Austria y las artes (1629-1679). Madrid, Fundación de Apoyo al Arte Hispánico, 2005, pp. 132-135. Don Juan José compró otras colgaduras en Sicilia y regaló una colgadura de cama de coral con ocasión del segundo parto de la reina Mariana de Austria en 1655, cuyo adorno de entrelazos es conocido por el lienzo de Sebastián Muñoz de las exequias de la reina María Luisa de Orleans (1689), ocasión en la que se utilizó esta colgadura.

46. Di NatAle, Maria Concetta: Splendori di Sicilia. Arte Decorative dal Rinascimento al Barocco. Milán, Regione Siciliana, 2001, pp. 551-552. 
Messina ideado por Filippo Juvarra en I70I. Ambos modelos tienen su precedente en los paños de la colgadura de la colección real española ${ }^{47}$.

El gusto de los bordadores napolitanos y sus clientes por las galerías, templetes y perspectivas adornadas de flores y frutos, que parece haber persistido en Sicilia durante todo el siglo xvil y principios del xvill, se agota en Nápoles mucho antes. En las décadas finales han desaparecido los altorrelieves realizados con sobrepuestos y rellenos, y, sobre todo, los ilusionismos espaciales que procuraban aquellos. La vegetación y los animales se desplazan hacia los bordes - que se acercan a lo que es una orla-, los paisajes pierden importancia y la historia figurada ocupa gran superficie y se convierte en el motivo principal, con lo que los paños bordados se aproximan a los tapices en el efecto visual. No conocemos ejemplares que testimonien la evolución de uno a otro estilo, aunque debieron existir, y por ello parece brusco el cambio entre las colgaduras de pérgolas, de estética cercana a lo renacentista, y las que se hacen a fines de siglo, plenamente barrocas, de las que son prototipo los seis paños (fueron también diez) de las virtudes de Santo Tomás de Aquino, realizados hacia i687, que se conservan en Santo Domingo de Nápoles. Algo más tardíos pero cercanos en el estilo son los cinco paños (solo dos completos) de la colgadura napolitana del Victoria and Albert, con pasajes de la Jerusalén liberada de $\mathrm{Tasso}^{48}$.

A la luz de los ejemplares examinados, abordamos por último posibles cuestiones iconográficas relacionadas con la colgadura del Museo Arqueológico. Su principal originalidad radica en sus asuntos, exclusivamente zoológicos, con animales salvajes de los que cuatro son fieras - dos leones, una pantera y un oso, encadenados-y otros no: un pequeño mono también con cadena y un ciervo. Los cuatro restantes son animales domésticos: un perrillo, un carnero y dos mastines que llevan collar pero no ataduras.

La afortunada existencia del inventario de I64I antes mencionado, en que se relaciona la tapicería cuando constaba sólo de tres paños, facilita un tanto la labor de interpretación. Los animales representados eran feroces, y su disposición y postura permiten deducir que estaban pensados para colocar la pantera a la izquierda, el león tumbado a la derecha y el oso atacando a un perro - el único paño que cuenta con dos animales - en el centro. Podían estar destinados a verse en una sola pared, o bien en tres paredes contiguas. El oso, en la Iconología de Ripa, es el animal cuya cabeza debe servir de tocado a la Ira: «Se le pone cabeza de Oso porque dicho animal es inclinadísimo a la Ira, de donde viene el proverbio: Fumantem viri nasum ne tetigeris ${ }^{49}$. La pantera es el más fiero y cruel de los animales, del que Aristóteles dice que jamás se domestica ${ }^{50}$, pero también símbolo del engaño, y por ende, de la astucia, porque permite que los animales se aproximen a contemplar su bella piel,

47. Por ejemplo: «Ottro paño de la misma Suertte, ttodo él de prespectiuas Con Vnos Árboles y Un Corredor y en él Unos pájaros y Árboles con granadas...» y «otro Paño de Un Palacio en Prespectiua con Una Ninfa enzima de la fuente y Un faetton en lo más alto...» (FERNÁNDEZ BAYTón, Gloria, op. cit., p. 279).

48. Musella Guida, Silvana: «Percorsi incrociati. La fortuna degli arazzi ricamati nella Napoli di fine Seicento», Confronto. Studi e ricerche di storia dell'arte europea, Pozzuoli (Napoli), 6-7 (2005/2006), pp. 97-122.

49. RıPA, Cesare (ed. Madrid, Akal, 1987): Iconología. Siena 1613 (4. ${ }^{a}$ ed.), t. I, p. 538.

50. Idem, p. 316 . 
lo que aprovecha para apresarlos ${ }^{51}$. El león que está tumbado simula dormir, pero mantiene un ojo abierto, símbolo de la vigilancia «porque según cuenta Pierio Valeriano, [el león] nunca abre los ojos por completo sino mientras duerme» $5^{2}$. Sobre la pantera aparecen unos gallos, que, según Ripa, por ser de Condición celosa ${ }^{53}$, ante cualquier Sospecha ${ }^{54}$ se ponen en Vigilancia ${ }^{55}$. ¿Podrían encerrar estos tres paños un discurso programático de Medina de las Torres sobre su forma de ejercer el virreinato? La vigilancia (león) y la astucia (pantera) comparten su existencia con la fiereza del oso al enfrentarse al enemigo (oso atacando al perro).

Los seis paños que aparecen en I655 añadidos a los tres de I64I responden dos a dos a la misma simetría especular que tenían la pantera y el león ya examinados. Tres de los cuatro paños grandes tienen animales que vuelven su cabeza hacia atrás en un giro completo, uno hacia la izquierda (ciervo) y dos hacia la derecha (perro y carnero). La denominación del carnero en el inventario - anticervo- nos inclina a emparejarlo con el ciervo. El lebrel sería, por tanto, compañero del otro león, el único que mira al frente. El perrillo ${ }^{56} \mathrm{y}$ el mono han de ser necesariamente pareja por aparecer en los paños estrechos, probablemente entrepuertas o entreventanas ${ }^{57}$.

No resulta simple encontrar un significado político a unos animales semejantes. Ripa hace del lebrel un signo de Fidelidad ${ }^{5}$, lo que encaja bien con el águila que aparece entre la hojarasca del techo de la pérgola, símbolo de Majestad regia ${ }^{59}$. Hay otra interpretación también conveniente mencionada por Giovio ${ }^{60}$ en un emblema que representa un lebrel sentado y erguido, cuyo mote dice Quietam nemo impune lacesset, esto es, "A nadie inquieto si no me molesta», sin duda un principio que debía observar cualquier buen gobernante. El ciervo es símbolo de prudencia, y aparece a los pies de la representación de esa virtud en la imagen de Ripa ${ }^{61}$. El carnero, por el contrario, es un animal belicoso que sirve y acompaña para caracterizar al emblema de la rivalidad ${ }^{62}$. El león erguido con actitud pacífica podría representar la grandeza de ánimo, porque, según Ripa recordando a los egipcios, ningún otro cuadrúpedo supera su arrojo y valentía ${ }^{63}$. El mono es un animal al que se asocian cualidades difíciles de compaginar con virtudes que deben adornar a un virrey, si bien la astucia que Aristóteles atribuía a los de su especie ${ }^{64}$ encajaría bien en un

\footnotetext{
51. Idem, p. 340.

52. Idem, t. II, p. 421. Encima hay un pavo real, símbolo de sabiduría.

53. Idem, t. I, p. 211.

54. Idem, t. II, p. 326.

55. Idem, p. 420

56. No tiene collar como el perro y el ciervo, y en cambio sí llevan el lebrel y el carnero, aunque no están encadenados como los leones, el leopardo, el oso y el mono.

57. Flanquearían al único paño con dos animales, el del oso y el perro.

58. Idem, t. ।, p. 415 .

59. Idem, t. II, p. 37 .

6o. Gıovio, Paolo: Dialogo dell'Imprese Militari et Amorose di Monsignor.... Lyon, 1574, pp. 41-42, cit. por GARCíA Mahiques, Rafael: Juan de Borja y el universo cultural de la emblemática. Valencia, 1995, p. 140 (http://wwW.uv.es/ mahiques/empresas_libro_B.pdf).

61. RipA, Cesare, op. cit., t. II, p. 234.

62. Idem, t. II, pp. 277-278.

63. Idem, t. I, pp. 468. En la zona superior de ese paño hay un armiño, símbolo de realeza como el león.

64. Idem, t. I, p. 117. En los paños del ciervo, el león con la bola y el oso hay también un mono, situado en la parte superior.
} 
gobernante inspirado en ideas maquiavélicas. El mono sería así una alternativa a la zorra, el más caracterizado de los animales astutos. Su compañero, el perrillo faldero, significa la Lealtad ${ }^{65}$.

Este rápido recorrido por la hipótesis de que la colgadura sea un repertorio de emblemas de las virtudes del gobernante tiene como alternativa el que esos paños -cuya función de extender el paramento mucho más allá de sus límites naturales mediante un efecto óptico hemos examinado antes - fueran simplemente una galería de animales con trasfondo exclusivamente decorativo, a modo de casa de fieras o menagerie. Este trasfondo político e ideológico se apoya en la excepcionalidad del conjunto, que revelan las fuentes que aportamos, así como la propia visión del mismo, ya que por fortuna ha llegado hasta nuestros días intacto.

65. Idem, t. II, p. 14. Encima se reconoce un loro. 


\section{APÉNDICE DOCUMENTAL}

AHPM. prot. 8I7I, fol. 583-586v.

Auttos, obligación y carta de pago sobre el entrego de una colgadura de oro y sedas al señor Príncipe de Astillano. 1672, 23 de diziembre.

Don Nicolás Garrafa y Guzmán, Príncipe de Astillano, Duque de Sanlúcar la Mayor y de Medina de las Torres, digo que entre otros vienes que estaban en poder de la excelentísima señora Condesa de Oñate y Villamediana y se an depositado en Juan de Santiago ay una colgadura bordada de oro y sedas, tassada en ochenta mill ducados poco más o menos, y por el descuido con que se a tenido se halla maltratada, que si luego no se trata de aderezar, no tendrá después forma de aderezarse, y se perderá de todo punto, perjudicándose todos los interesados en cantidad tan considerable como es el valor de la dicha colgadura si se da lugar a que quede inútil, para cuyo remedio, y por ser yo el principal interesado, assí porque la dicha colgadura es mía propia, como se verificará a su tiempo, como por los grandes créditos y derechos que me asisten contra todos los vienes depositados, suplico a vuesa merced mande que, obligándome yo en forma a tener de manifiesto la dicha colgadura siempre que se ordenare, se me mande entregar para el efecto referido de hazer que se adereze y componga en la dilación se puede ocasionar grave daño, y en mandarlo assí no puede aver perjuicio, y es de justicia, la qual pido a vuestra señoría. Nicolás de Guzmán

Autto. Haciéndose obligación en forma por el excelentísimo señor don Nicolás Garrafa y Guzmán, Prínzipe de Astillano, Duque de Sabioneta y de Sanlúcar la Mayor y de Medina de las Torres, a ley de depósito de tener pronto y de manifiesto la colgadura de oro y sedas bordada que refiere esta petición para el efecto que en ella se aze mención, y que aderezada no usará della, y la bolverá al depósito en que está en Juan de Santiago, mercader de sedas, siempre que se mandare volver, se dé despacho para que el dicho Juan de Santiago entregue a su excelencia la dicha colgadura. El señor lizenciado don Juan Lucas Cortés, theniente de corregidor desta villa de Madrid lo probeyó en veinte y dos de diciembre de mil y seiscientos y setenta y dos años. Licenciado don Juan Lucas Cortés. Ante mi, Juan de Burgos.

Obligación. En la villa de Madrid a veinte y tres días del mes de diziembre de mill y seiscientos y setenta y dos años, por ante mi el escribano del número y testigos, el excelentísimo señor don Nicolás Garrafa y Guzmán, Príncipe de Astillano, Duque de Sabioneta y de Sanlúcar la Mayor y de Medina de las Torres, dijo su excelencia que en cumplimiento del auto antes deste probeydo por el señor licenciado don Juan Lucas Cortés, theniente de corregidor desta dicha Villa, ante el pressente escrivano en beinte y dos de este mes se obliga y obligó su excelencia a ley de depóssito de tener y que tendrá pronta y de manifiesto la colgadura de oro y sedas bordada que refiere el pedimento dado por su excelencia y que refiere el dicho auto, que se compone de nueve paños, dosel y cinco zenefas dél y es todo bordado, en la forma siguiente:

Los canpos y cuerpo de todos los paños es bordados de matizes de sedas en forma de país con unas colunas salomónicas a los lados de oro de medio relieve, enlazadas 
diferentes flores bordadas de matizes, y en la parte de abajo un enladrillado que cierra una barandilla, tanbién de oro, y al pie de ella en cada paño un animal de medio relieve, diferentes jéneros bordado también de matizes de sedas, y en todos los dichos paños y dosel ay un escudo de las armas de su excelencia, la qual dicha colgadura pidió su excelencia, y por el dicho señor theniente se le manda entregar para adereçarla, y así se obliga su excelencia a hazerla adereçar, y la tendrá como ba referido a ley de depósito prontta y de manifiesto y que en qualquier tiempo que por auto del dicho señor theniente $u$ otro juez competente se le mande bolber al depósito en que al presente está en Juan de Santiago, mercader de sedas, lo cumplirá sin escusa ni dilación alguna, y ofreze su excelencia y se obliga a que no dispondrá ni usará de la dicha colgadura para otro fin ni efecto alguno más que para el que la a pedido, pena de yncurrir en las leyes que proíben a los depósitos usar de las cosas depositadas en ellos, y luego que la dicha colgadura se aya aderezado en toda forma, se obliga su excelencia a que sin preceder auto ni ynterpelación alguna bolberá al dicho depósito la dicha colgadura, de la qual su excelencia, en conformidad del dicho autto, se instituye por berdadero depositario para que si fuere necesario se prozeda por los prebilexios, términos y leyes de depósito, y al cumplimiento de esta obligación y depósito y todo lo en ella contenido, el dicho excelentísimo señor Príncipe de Astillano se obligó y obligó todos sus vienes, rentas y estados, así libres como de mayorazgo, alodiales y feudales que tiene y posee en los reynos de España como en el de Nápoles y otras qualesquier parttes, y obligó asimismo todos y qualesquier oficios, acciones y derechos corporales o yncorporales que en qualquier manera le pertenezcan havidos y por haver, para que todo ello sin exceción de cosa alguna quede sujeto, obligado, y ypotecado al cumplimiento y seguridad del dicho depósito y obligación, y para la execución y cumplimiento de todo lo en ella contenido, su excelencia da todo su poder cumplido a las justicias y juezes del Rey nuestro sseñor, y en especial al dicho sseñor theniente para que a su excelencia y sus bienes puedan apremiar y compeler como por sentencia pasada en autoridad de cossa juzgada, y renuncia qualquier fuero o prebilexio que le competa para no se poder valer de él ni ser oydo en rrazón de ninguna declinatoria que proponga contra la jurisdición del dicho sseñor theniente $u$ de otra qualquier justicia que de este negocio conozca, a quien desde luego expecialmente se somete su excelencia, y así lo otorgó y firmó su excelencia, a quien yo, el esscribano, doy fee que conozco, siendo testigos don Juan Tribiño y Pedro Martínez, criados de su excelencia, y Thomás de Elejaga, residentes en esta Cortte. Nicolás de Guzmán. Ante mi, Juan de Burgos.

Diose libramiento por el señor theniente para que Juan de Santiago entregase a su excelencia la colgadura, y dio carta de pago qual está adelante.

Auto. Attentto la obligación hecha por el excelentísimo señor Príncipe de Astillano se dé libramiento y despacho para que Juan de Santtiago, depositario de los vienes que quedaron del excelentísimo señor Duque de Medina de las Torres, entregue a su excelencia la colgadura vordada de oro y sedas, dosel y zenefas que refiere la dicha obligazión, dando carta de pago el señor licenciado don Juan Lucas Cortés, theniente de corregidor desta villa de Madrid, que lo probeyó en ella a veynte y tres de diciembre de mil y seiscientos y settenta y dos años. Licenciado Cortés. Ante mi, Juan de Burgos.

Carta de pago de una colgadura para Juan de Santiago. 1672, 23 de diziembre.

En la villa de Madrid a veinte y tres días del mes de diziembre de mill y seiscientos y setenta y dos años, por ante mi el sscribano y testigos, el excelentísimo señor don Nicolás Garrafa y Guzmán, Príncipe de Astillano, Duque de Sabioneta y de Sanlúcar 
la Mayor y de Medina de las Torres, dixo su excelencia comfiessa haver rezivido de Juan de Santiago, mercader de sedas en la Puertta de Guadalajara, depositario de los vienes y alajas que quedaron por fin y muertte del excelentísimo señor Duque de Medina de las Torres, su padre, es a saver, una colgadura de oro y sedas bordada, que se compone de nueve paños, dosel y zinco zenefas, que todos los canpos y cuerpos de dichos paños es bordados de matices de sedas en forma de país con unas colunas salomónicas a los lados de oro de medio relieve, enlaçadas de diferentes flores bordadas de matizes, y en la partte de abaxo un enladrillado que cierra una barandilla, también de oro, y al pie de ella en cada paño un animal de medio reliebe de diferentes jéneros bordado tanbién de matizes, y en dichos paños y dosel ay escudos de las armas de su excelencia, la qual dicha colgadura de nuebe paños, dosel y cenefas, por libramiento del sseñor lizenciado don Juan Lucas Cortés, theniente de corregidor de esta Villa, de oy día de la fecha, refrendado del presente sscribano, está mandado que el dicho Juan de Santiago la entregue a su excelencia para efecto de aderezarla y tenerla pronta y de manifiesto a ley de depósito, y que adereçada no usará de ella y la bolberá al depósito siempre que mandare, como más particularmente se declara en el dicho libramiento, que se entrega original con esta carta de pago, en cuya birtud su excelencia rezive del dicho Juan de Santiago la dicha colgadura, dosel y zenefas, y se da por satisfecho y entregado a toda su boluntad por la haver rezivido realmente y con efecto, y por no parezer su entrego de pressente, renuncia su excelencia las leyes y excepción de la cossa no bista, y da carta de pago en forma al dicho Juan de Santiago, y así lo otorgó y firmó su excelencia, a quien yo, el escribano, doy fee que conozco, siendo testigos don Juan Tribiño y Pedro Martínez, criados de su excelencia, y Thomás de Elejaga, residentes en esta Cortte. Nicolás de Guzmán. Passó ante mi, Juan de Burgos. 


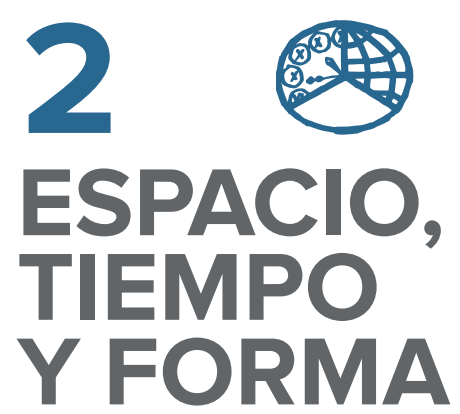

\section{Miscelánea $\cdot$ Miscellany}

David Gimilio Sanz

Poder, humanismo y religiosidad en tiempos del Patriarca Juan de Ribera en Valencia: su colección de escultura clásica / Power, Humanism and Religiosity at the Time of the Patriarch Juan de Ribera in Valencia: his Collection of Classical Sculpture

$$
41
$$

JUAN CRUZ Yábar

De Nápoles a Madrid: la colgadura de los animales del duque de Medina de las Torres / From Naples to Madrid: the Animals Wall Hanging of the Duke of Medina de las Torres

\section{9}

GIOIA ELIA

La etapa italiana de Valentín Carderera (1822-1831) / Valentín Carderera's Italian Sojourn (1822-1831)

\section{María josé Pena García}

Estéticas de lo cotidiano: cuatro visiones de la realidad en la pintura española contemporánea / Every Day Life Aesthetics: Four Visions of Reality in Contemporary Spanish Painting

\section{JuAn José SÁnCHEZ GonzÁlez}

La construcción de un espacio de poder: los castillos del estado señorial de Feria / The Construction of an Space of Power: Castles of the Manorial State of Feria

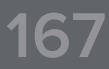

\section{José JaVIer BarRanquero Contento}

La transformación de los modelos arquitectónicos medievales en el Priorato de Uclés: las parroquias de Dosbarrios y Villanueva de Alcardete / The Transformation of the Medieval Architectural Models in the Priorato de Uclés: the Parish Churches of Dosbarrios and Villanueva de Alcardete 